
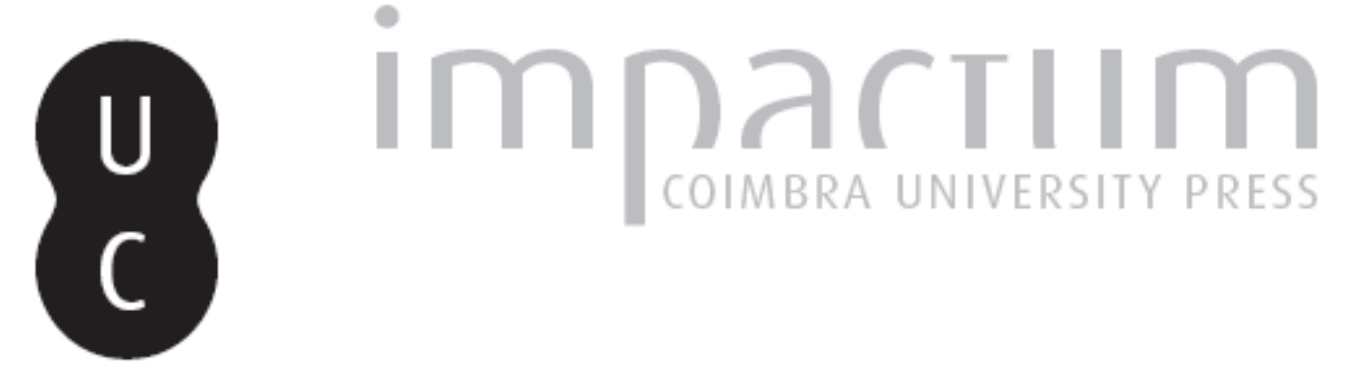

Dove va il Portogallo?: a Revolução de Abril como grande acontecimento discursivo Autor(es): $\quad$ Gomes, Marco

Publicado por: Imprensa da Universidade de Coimbra

URL persistente:

URI:http://hdl.handle.net/10316.2/42410

DOI:

DOl:https://doi.org/10.14195/0870-8584_9_4

Accessed : $\quad$ 26-Apr-2023 10:32:55

A navegação consulta e descarregamento dos títulos inseridos nas Bibliotecas Digitais UC Digitalis, UC Pombalina e UC Impactum, pressupõem a aceitação plena e sem reservas dos Termos e Condições de Uso destas Bibliotecas Digitais, disponíveis em https://digitalis.uc.pt/pt-pt/termos.

Conforme exposto nos referidos Termos e Condições de Uso, o descarregamento de títulos de acesso restrito requer uma licença válida de autorização devendo o utilizador aceder ao(s) documento(s) a partir de um endereço de IP da instituição detentora da supramencionada licença.

Ao utilizador é apenas permitido o descarregamento para uso pessoal, pelo que o emprego do(s) título(s) descarregado(s) para outro fim, designadamente comercial, carece de autorização do respetivo autor ou editor da obra.

Na medida em que todas as obras da UC Digitalis se encontram protegidas pelo Código do Direito de Autor e Direitos Conexos e demais legislação aplicável, toda a cópia, parcial ou total, deste documento, nos casos em que é legalmente admitida, deverá conter ou fazer-se acompanhar por este aviso.

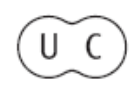




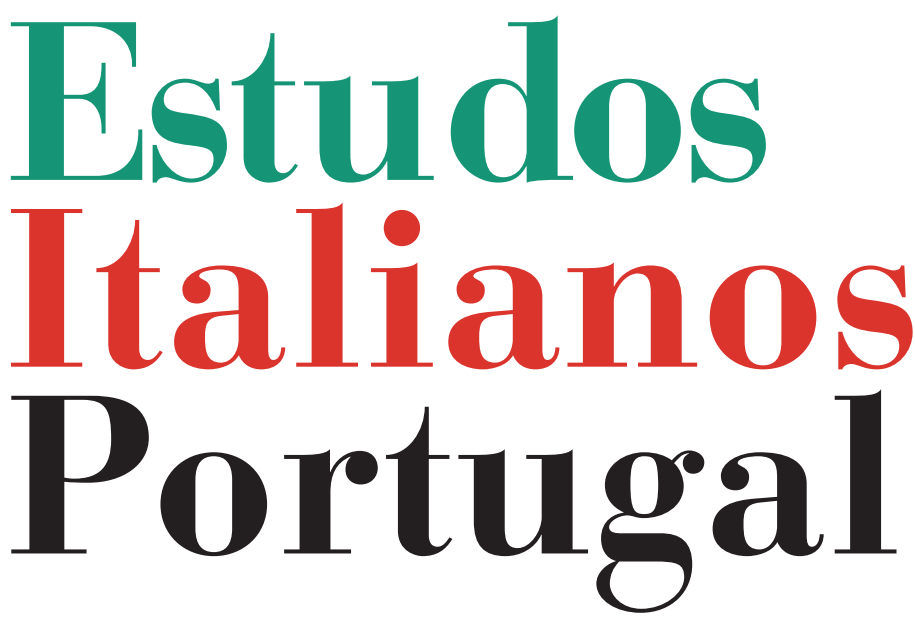

Instituto

Italiano

de Cultura

de Lisboa

Nova Série

$\mathbf{N}^{\circ} 9$ 


\section{DOVE VA IL PORTOGALLO? A REVOLUÇÃO DE ABRIL COMO GRANDE ACONTECIMENTO DISCURSIVO}

Marco Gomes*

"La DeCisione del Consiglio Superiore della Rivoluzione di escludere dalla competizione elettorale tre partiti, tra i qual la Democrazia Cristiana, ha scosso l'opinione pubblica portoghese, non meno di quella di tutti gli altri paesi europei”, escrevia o deputado Michele Achillii em Avanti!, em Março de 1975. O título "Dove va il Portogallo?" secundava o parágrafo-guia do extenso artigo do órgão oficial do Partido Socialista Italiano ${ }^{2}$. São enunciados, de alguma forma, elucidativos quanto às repercussões dos acontecimentos portugueses, cujo sentido se encontra em consonância com outras afirmações de jornalistas italianos.

Por altura do arranque da campanha para as eleições da Assembleia Constituinte, Sandro Ottolenghi ${ }^{3}$ lançava a mes-

* Mestre em História das Ideologias e Utopias Contemporâneas, bolseiro de doutoramento da FCT para a elaboração de uma tese dedicada ao impacto do 25 de Abril em Itália através da imprensa, editou o livro Comunicação na revolução de Abril. 1974-1976 (Coimbra, Minerva, 2009).

${ }^{1}$ Michele Achilli, “Dove va il Portogallo?”, Avanti!, 23-3-1975, p. 14.

${ }^{2}$ A partir de aqui: PSI; além disso: Movimento Popular de Libertação de Angola: MPLA; Partido da Democracia Cristã: PDC; Movimento das Forças Armadas: MFA; Processo Revolucionário Em Curso: PREC; Polícia Internacional de Defesa do Estado/Direcção-Geral de Segurança: PIDE/DGS; Partido Comunista Português: PCP; Partito Comunista Italiano: PCI; Partido Socialista Português: PS.

${ }^{3}$ Sandro Ottolenghi, "Parlano i capi del Portogallo", L'Europeo, 3-4-1975, p. 28. 
ma questão: "Dove va il Portogallo?”. O enviado especial de L'Europeo deslocou-se a Lisboa e traçou o diagnóstico: "Il Portogallo è sotto accusa, è diventato il punto focale della politica internazionale, quel che vi accade ha avuto, soprattutto in Italia, riflessi inaspettati. [...] Si sta giocando una carta molto importante nel poker dei rapporti di forze e del futuro d'Europa. Forse anche del mondo".

Formulada em diversas ocasiōes por atores políticos, jornalistas e comentadores, a pergunta Dove va il Portogallo? constitui um pertinente ponto de partida para discorrer sobre o objeto de estudo desta reflexão: o impacto da Revolução de Abril no setor de informação e nos campos político e social em Itália. A interrogação afigura-se sugestiva na medida em que remete para uma certa perplexidade dos locutores. Essa perplexidade, na verdade, foi sempre assistida por ceticismo, os sentimentos que mais adesão suscitaram, no olhar externo, sobre o curso revolucionário português.

Mas os enunciados de Michele Achilli e Sandro Ottolenghi subentendem, também, vários planos, por exemplo, no âmbito da análise do discurso, que vão do mapeamento das vozes à identificação dos sentidos. Não obstante esta pesquisa persiga objetivos mais modestos do que o estudo das formaçôes discursivas, é possível verificar que a linguagem do deputado socialista e do jornalista do mítico hebdomadário remete para o envolvimento interessado dos locutores, a existência de vozes (polifonia), a formulação de um quadro de sentidos que retoma outras significações produzidas em situaçôes anteriores (intertextualidade). O dialogismo está presente em toda a linguagem (Bakhtin, 1986: 66), favorecendo tanto as relações entre discursos (interdiscursividade) como as relações entre sujeitos (intersubjetividade). Qualquer discurso é arquitetado de forma intersubjetiva e isso exige que seja entendido como histórico e determinado pelos enquadramentos (frame) sociais e culturais, aquilo que Goffman (1974-1986: 7-11) designa o conjunto de princípios de or- 
ganização que governam os acontecimentos sociais e o nosso envolvimento subjetivo neles.

Vislumbrados por largos setores da opinião pública italiana como agentes vocacionados para estabelecer uma ditadura militar marxista ou um qualquer regime alinhado com as matrizes das democracias populares de leste ou das democracias diretas terceiro-mundistas, a frontal reprovação quanto ao destino político preconizado pelos militares de Abril não esgota, no entanto, o enquadramento italiano sobre a Rivoluzione dei garofani. Vários coletivos da esquerda radical, de $I l$ Manifesto à Lotta Continua ou Avanguardia Operaia, viveram a revolução in loco e de forma apaixonada, como se se tratasse de reabilitar os sonhos depositados na dinâmica de 1968 ou no autunno caldo de 1969.

O sentido da questão Dove va il Portogallo? suscitou episódios políticos e sociais críticos, sentimentos de vituperação, solidariedades e entusiastas reações. Originou inflamadas polémicas entre intelectuais, políticos, comentadores, jornalistas e agentes sociais ${ }^{4}$ discussões no parlamento e nas assembleias municipais e regionais, preferências políticas em detrimento de opções editoriais. Conduziu os meios de comunicação a dissemelhantes chaves de leitura e representações da mundividência.

Desde o início de 1975 que os acontecimentos portugueses foram ocupando, consistentemente, os espaços nobres dos órgãos de informação italianos, não apenas aqueles dedicados à atualidade internacional, mas igualmente as secçóes focalizadas na política interna da península. Não poucos foram os momentos em que os campos político e jornalístico se apropriaram de temáticas dimanadas da revolução e se lançaram em processos de instrumentalização, resgatando

\footnotetext{
${ }^{4}$ Os espaços dedicados pela imprensa italiana à voz dos leitores constituem um excelente barómetro para aferir o interesse que a Revolução de Abril suscitou na opinião pública.
} 
assuntos com maior ou menor exposição mediática com o intuito de gerar novos acontecimentos discursivos (Foucault, 1969-2005) e desenvolvimentos supletivos.

Efetivamente, a Revolução de Abril conferiu ao país de Camões uma ressonância mediática sem precedentes e alterou, em determinados momentos, o ritmo e os conteúdos da praxis política italiana ${ }^{5}$. A moldura que enforma as repercussões do curso revolucionário português em Itália é, portanto, caraterizada pelo envolvimento interessado e polifónico dos agentes políticos, sociais e culturais, bem como pela abundância de sentidos (enquadramentos) que oscilam entre sentimentos de identificação e conflitualidade. Imperou, sobretudo, a prática da exegese como meio de definir uma determinada posição discursiva contra, a favor ou a partir do Outro (português).

Metodologicamente, pretende-se elaborar um inventário dos discursos (enunciados) e acontecimentos desencadeados em Itália pela dinâmica revolucionária portuguesa. Na esteira da perspetiva de Michel Foucault (1969-2005: 57), o enunciado é aqui trabalhado como um acontecimento "que nem a língua nem o sentido podem esgotar por inteiro", proporcionando a si mesmo uma existência remanescente na esfera de uma memória ou na materialidade das palavras impressas e verbalizadas. Tal como o acontecimento, o enunciado é único e oferece-se ao uso e à repetição, torna-se tema de apropriação, transforma-se, reativa-se.

No contexto desta pesquisa, a problematização foucaultiana convida a observar os eventos arrolados enquanto acontecimentos discursivos, quer sejam encontros entre atores políticos e sociais, manifestações, confrontos físicos entre ativistas políticos ou iniciativas culturais, quer sejam discussões no âmbito de sessões parlamentares, de congressos, declarações

${ }^{5}$ A questão portuguesa foi um dos temas em maior destaque durante o XIV Congresso do Partido Comunista Italiano e as eleiçôes Regionais e Administrativas de 1975. 
à imprensa, notícias ou reportagens destinadas a revelar tomadas de posição ou determinadas análises e considerações.

Elaborou-se uma grelha taxionómica orientada para determinar o grau de exposição pública e a frequência de desenvolvimentos supletivos (Elevado-Regular-Reduzido) associados aos acontecimentos inventariados. A classificação desses acontecimentos discursivos processou-se, por um lado, a partir dos critérios de noticiabilidade (Galtung, Ruge, 1965; Chaparro, 1994; Wolf, 1985-2001) que determinam o newsmaking e, por outro, através de uma exaustiva análise exploratória das mais importantes publicaçóes italianas, entre 25 de Abril de 1974 e 2 de Abril de 1976 (aprovação da Constituição da República), num universo que ultrapassa os 150 títulos. Desse universo constam os principais jornais diários, semanários e mensários de grande informação, bem como a imprensa partidária ou de tendência, além das publicações periódicas de referência.

\section{A MUlTipliCidADE TEMÁTICA DA QUESTÃO PORTUGUESA}

A primeira categoria respeita aos acontecimentos discursivos com reduzida exposição pública e frequência de desenvolvimentos supletivos. São aqueles eventos que, possuindo valor mediático, irrompem na substância da novidade de forma, muitas vezes, pontual ou pouco continuada, com reduzidas probabilidades de ocuparem os espaços nobres da informação. $\mathrm{O}$ valor desta categoria não reside tanto no impacto mediático dos acontecimentos que congrega, mas antes na diversidade temática que esses representam, sem dúvida um indicador importante para avaliar as réplicas da também denominada questão portuguesa.

A Revolução de Abril motivou, neste sentido, numerosas iniciativas políticoculturais organizadas pela sociedade civil ou pelas instituições democráticas, desde conferências de imprensa, debates, mesas-redondas, convénios ou apre- 
sentações de livros. Esses encontros visavam discutir o rumo político alvitrado por Lisboa e as réplicas internacionais do processo revolucionário, juntando figuras, na sede da revista Sette Giorni (Julho, 1975), como o comunista Sergio Segre, o democratacristão Angelo Sanza ou o republicano Antonio Del Pennino. O mesmo sucedeu em Florença (Maio, 1975) com o encontro organizado por três círculos culturais locais (Rosselli, Gramsci, Panzieri), sobre "Socialismo e democrazia in Portogallo", em Turim (Agosto, 1975) sobre "La questione portoghese" ou, entre tantas outras iniciativas, na Festa comunista de L'Unità.

$\mathrm{O}$ caso de Angola envolveu, igualmente, a opinião pública e convocou representantes do MPLA para testemunhar, em Itália, a experiência fratricida da guerra civil que, já declarada a independência, opôs os movimentos de libertação africanos. Numa altura em que circulavam notícias sobre o recrutamento, na Europa, de mercenários para os conflitos em Moçambique (entre ex-colonialistas e novas autoridades, em 1974) e em Angola (1975-1976), a Itália foi associada ao fluxo de forças e de material militar que seguia para a África Austral. Não obstante os desmentidos oficias, várias foram as notícias que deram conta da partida, do porto de Génova, de mercenários italianos para Moçambique ou Angola, bem como o envio de uniformes militares, dissimulados em caixas de medicamentos, para a Frente Nacional de Libertação de Angola.

À semelhança dos debates, conferências e mesas-redondas, os intercâmbios político-culturais são também expressão do interesse depositado nesta fase de transição para a democracia. Diversas delegações partidárias ou personalidades do mundo da cultura deslocaram-se a Portugal para dar o seu contributo e observar uma conjuntura que suscitou sentimentos contraditórios. De salientar, neste contexto, as viagens organizadas pelos coletivos da esquerda radical, empenhados em longos debates no parque de campismo de Monsanto e no turismo político que caraterizou os programas do ano de 1975. 
Em sentido contrário, foi intenso o fluxo de personalidades que se deslocaram à Península Itálica. Mário Soares, Salgado Zenha e Tito de Morais não dispensaram contatos com o aparelho do PSI. No âmbito das relações diplomáticas bilaterais, Costa Gomes, Melo Antunes e Martins Guerreiro privaram com as mais altas figuras do edifício político italiano. Maria Barroso, por exemplo, participou, em Roma, no seminário dos partidos socialistas sobre a condição feminina. A convite do Circolo Culturale di Documentazione Azione e Studi, o major Sanches Osório (PDC), já no exílio, procurou explicar, em Roma e Turim, a sua perspetiva da revolução, enquanto o bispo de Aveiro, Manuel de Almeida Trindade, aconselhou-se com as hierarquias eclesiásticas do Vaticano a respeito do "caso Rádio Renascença”. Não esquecendo ainda os representantes dos movimentos de libertação africanos, interessados em fazer da capital italiana um ponto de passagem para contatos internacionais, como sucedeu com o primeiro-ministro da Guiné Bissau, Luís Cabral, e especialmente com elementos do MPLA.

As problemáticas dimanadas da questão portuguesa agitaram, de facto, o espaço público italiano. Motivaram incidentes entre estudantes democratas-cristãos e grupos de extrema-esquerda em Pistoia (Março de 1975), ou entre manifestantes de diversas formações políticas no âmbito do documento aprovado pelo Conselho Municipal de Veneza (Março, 1975), declaração que condenava a decisão dos militares de Lisboa em suspender o Partido da Democracia Cristã das eleições para a Assembleia Constituinte. Foi notícia a concentração de 50 mil manifestantes em Roma (Abril de 1975), na Piazza della Repubblica ${ }^{6}$, em solidariedade com o povo português e o MFA, bem como a manifestação comemorativa do sucesso dos socialistas de Mário Soares nas eleições de 25 de Abril de 1975, organizada, na capital romana, pela Federazione Giovanile Socialista (Abril, 1975).

\footnotetext{
${ }^{6}$ Manifestação organizada pela esquerda radical.
} 
A animosidade com que os coletivos da esquerda radical se dirigiram a Mário Soares - "Soares Fascista" - aquando de mais uma manifestação por Portugal, em Outubro de 1975, com 100 mil pessoas, constitui um episódio elucidativo quanto ao clima de conflitualidade que grassava na sociedade italiana, e, por isso, permeável às réplicas da Península Ibérica. Os murais ou manifestos políticos do "Soares fascista" logo deram azo a um debate, no diário Il Messaggero, sobre o vandalismo e a infantilidade atribuída à prática política dos grupos extraparlamentares.

A inequívoca reprovação manifestada pelos partidos com assento parlamentar a respeito da suspensão do PDC perpassou para as instituições. O Ministério dos Negócios Estrangeiros convocou o embaixador português em Roma com o intuito de demonstrar viva preocupação pelo impacto dos acontecimentos portugueses na opinião pública italiana. Dezenas de conselhos comunais, de Milão, Florença, Turim, Forlì, Veneza, apenas para mencionar alguns, emitiram documentos que consideravam as diretivas dos oficiais de Abril graves e contrárias ao espírito democrático, tendentes a regredir o processo de libertação do fascismo.

O PREC comportou determinados valores e condutas impossíveis de ignorar, por exemplo, no contexto quer do processo de democratização das Forças Armadas italianas, quer dos esforços tendentes a consagrar a unidade sindical. No primeiro caso, trata-se de uma questão bastante ecoante em cidades como Roma e Milão, através dos protestos dos oficiais de baixa patente (reivindicações económicas) que depressa receberam o apoio dos grupos da esquerda radical, alargando assim o debate para a esfera da ideologia e da disciplina. Escrevia Il Giornale: "In questo momento i sergenti sono pressati da due forze: da una parte il meccanismo burocraticoistituzionale che si rifiuta di capire il malcontento [...]; dall'altra, le sirene del pansidacalismo ad oltranza che parafrasano gli slogans suadenti del pasticciaccio portoghe- 
se"7. Mário Soares chegou a participar num convénio, em Roma (Dezembro, 1975), sobre o descontentamento nas Forças Armadas italianas.

No segundo caso, o modelo de unicidade sindical estabelecido em Portugal surgiu como um paradigma que importava rejeitar quando, em Itália, se olhava para o longo e conturbado processo de união das diferentes federações sindicais. Em declarações ao Corriere della Sera, o sindicalista Bruno Storti ${ }^{8}$ fez notar que não interessava um sindicato único de regime, como desejara o fascismo italiano e, em Portugal, os comunistas tinham vaticinado. Antes uma matriz unitária plural e de livre escolha associativa entre as federações já constituídas democraticamente.

O projeto social perseguido pelos fautores do 25 de Abril contemplou ainda a revisão da Concordata assinada entre o Estado português e o Vaticano, concedendo a um cidadão católico a possibilidade de solicitar o divórcio aos tribunais do Estado, mesmo que o contrato matrimonial, do ponto de vista moral e canónico, continuasse, na prática, indissolúvel. Os setores laicos italianos logo interpretaram esse acordo como um importante precedente tendente a influenciar as negociações entre Roma e o Vaticano no âmbito da revisão da Concordata assinada em 1929.

Cumpre, por último, salientar a não menosprezável produção caricatural e cartoonista que, inserida amiúde nos esquemas de apropriação temática e instrumentalização política, conciliou o jogo de referências às personalidades e aos acontecimentos portugueses com o mapa político autorreferencial italiano.

\footnotetext{
7 “La 'rivolta' dei sergenti”, Il Giornale Nuovo, 12-7-1975, p. 8.

${ }^{8}$ Citado por Ugo Indrio, "Storti: abroghiamo gli articoli dela Costituzione che parlano di regolare il diritto di sciopero", Corriere della Sera, 4-9-1975, p. 1.
} 
2. TERRORISMO, EMBARAÇOS DIPLOMÁTICOS E REPRESENTAÇÕES DA NARRATIVA JORNALÍSTICA

O segundo grupo de acontecimentos discursivos apresenta um valor-notícia médio e possui um regular grau de exposição pública e de desenvolvimento supletivo'. Nesta categoria, determinadas dinâmicas discursivas ocuparam os espaços centrais da informação, revelando índices elevados de negatividade, personalização, de expetativas em relação aos desenvolvimentos sucessivos (consonância, continuidade) e de familiaridade entre os eventos/personagens e o auditório (proximidade). A descoberta das reais finalidades da agência noticiosa Aginter-Press e as repercussões políticas do curso político pós-25 de Abril inserem-se nesta espiral mediática.

A queda do Estado Novo lançou novos dados sobre a atividade dos grupos de extrema-direita italianos, sobre a strategia della tensione e, em sentido lato, sobre o terrorismo negro e o seu conúbio com os serviços secretos. Em Maio de 1974 foram descobertos, em Lisboa, arquivos que não deixavam dúvidas quanto à existência de um centro de subversão fascista internacional com ramificações em diversos países, cuja célula em Portugal se encontrava dissimulada pela agência noticiosa Aginter-Press, dependente da PIDE/DGS. Esses documentos revelaram a operacionalidade e as ligaçóes de dezenas de colaboradores da agência noticiosa com algumas organizações italianas responsáveis pela onda de terrorismo negro. A Aginter-Press, estabelecida em Lisboa em meados da década de 60, mantinha, em Itália, estreitas relações com a agência Oltremare, controlada pelos serviços secretos.

Mas foram as representações jornalísticas das consequências internacionais da Revolução de Abril que enformaram, nesta categoria, os acontecimentos discursivos com maior ex-

\footnotetext{
${ }^{9}$ Os acontecimentos permanecem mais tempo na agenda mediática do que na categoria anterior.
} 
posição pública. A sucessão Salazar-Caetano emergiu como uma das quatro questóes capazes de perturbar a coexistência entre Washington e Moscovo e ameaçar, na Europa, o sistema de equilíbrios russo-americano da Guerra Fria ${ }^{10}$.

A influência de elementos comunistas nos governos provisórios portugueses e a incerteza quanto à permanência do país na NATO são temáticas cuja dimensão mediática foi relevante porque, primeiro, colocavam problemas ao nível da defesa do bloco ocidental (base da Lajes, informação sobre armas nucleares) e, segundo, surgiam ao mesmo tempo que outras duas questóes nada tranquilizadoras para o sistema de defesa liderado pelos Estados Unidos: a) possibilidade de os comunistas franceses e, sobretudo, italianos chegarem ao poder numa zona vital para a segurança do mediterrâneo; b) conflito de Chipre e consequente enfraquecimento do flanco oriental da $\mathrm{NATO}^{11}$.

Além de constituir objeto de polémica permanente no âmbito dos discursos de diversos partidos comunistas internacionais $^{12}$, Portugal constitui, igualmente, um tema recorrente quando se fala das reuniōes da Comunidade Económica Europeia (ajuda económica a Lisboa dependente da evolução para um regime democrático) e da transição espanhola pós-Franco. No caso de Madrid, a questão consistia em saber, grosso modo, se o regime espanhol, depois da experiência vizinha, conseguiria dar um passo indolor em direção às liberdades democráticas, se estava em condições de evitar o contágio revolucionário português, a violência e as convulsões sociais, a anarquia e a indisciplina nas Forças Armadas.

\footnotetext{
${ }^{10}$ As outras questões residem na sucessão de Franco, no futuro pós-Tito e na hipotética substituição do governo democrata-cristão em Itália e/ou na partilha de poderes com o Partido Comunista Italiano.

${ }^{11} \mathrm{O}$ conflito de Chipre envolveu a Grécia e a Turquia, dois membros da NATO. Teve como consequência a retirada da Grécia da organização de segurança atlântica e o embargo militar dos Estados Unidos à Turquia, perturbando o relacionamento entre estes dois países.

${ }^{12}$ De países como a URSS, China, Jugoslávia, Itália, França, Espanha ou partidos latino americanos.
} 
As analogias entre Portugal e Itália são uma componente essencial deste jogo dialógico e intertextual. Os dois países foram percecionados como os pontos problemáticos do sector meridional da Aliança Atlântica, devido à efetiva presença comunista nas estruturas de poder e governação (PCP) ou à elevada possibilidade de concretização desse cenário (PCI). Os paralelismos históricos evoluíram no sentido de considerar que Portugal apresentava condições muito semelhantes àquelas das regióes do sul de Itália, dominadas pelo baixo desenvolvimento económico, atraso cultural e por um clero conservador. Ou que a participação de vários partidos nos governos provisórios seguia o modelo italiano de 1946.

Esta última comparação foi objeto de polémica quando não poucos observaram que, diferentemente de Portugal, os partidos, durante o nascimento da República italiana, tinham sabido governar conjuntamente e podido exercer funções sem a tutela de um poder militar. O elemento fundamental de diferenciação residia, porém, na forte ligação que unia as classes populares, responsável não apenas pela edificação da resistência ao fascismo mussoliniano mas pela criação de laços de solidariedade entre as forças políticas tendentes a favorecer a tal coabitação no plano governativo.

As constantes analogias entre, de um lado, a natureza e o caráter das esquerdas portuguesas e, do outro, o percurso das esquerdas francesas, espanholas e italianas surgiu também de forma recorrente. As repercussões do conflito entre Cunhal e Soares foram transpostas para as esquerdas europeias na perspetiva de um obstáculo (português) que colocava em causa desígnios futuros, tanto do ponto de vista da união das esquerdas francesas como em relação ao projeto comunista do compromisso histórico, visando a coligação entre socialistas, comunistas e democratas-cristãos italianos.

A nova ordem impulsionada pelos oficiais de Abril revelou ainda as verdadeiras posições do embaixador italiano em Lisboa, Girolamo Messeri, sobre a evolução do processo políti- 
co português, posições que, denotando pouca simpatia pela nova ordem de Abril, redundaram em inflamadas altercaçōes devido ao modo como os interesses diplomáticos de Roma estavam a ser representados em Portugal. Girolamo Messeri foi, aliás, o grande protagonista do 'caso Ghioto' que contribuiu para acentuar a fratura entre o setor da informação e o poder político ao nível da liberdade de imprensa e da independência dos jornalistas.

\section{Portugal NA PRIMEIRA PÁGINA}

A categoria dos acontecimentos que apresentam maior valor-notícia e, por isso, se mantiveram por mais tempo no topo da hierarquia noticiosa deve a sua dominância, primeiro, ao XIV Congresso do PCI, depois, ao "caso República" e às eleiçôes Regionais de 1975 e, por último, ao documento conjunto do PCI e PSI. As duas primeiras sequências de eventos quase que se podem fundir numa só pelos seguintes motivos: em primeiro lugar, a apropriação de temáticas suscitadas pelo curso revolucionário pós- 25 de Abril e a consequente instrumentalização para efeitos de política interna representam uma linha transversal a esses três acontecimentos discursivos; em segundo, os diversos comentadores de diferentes tendências políticas avaliaram os desenvolvimentos da conferência comunista como o início da campanha para as eleições de 15 de Junho.

Quanto à declaração comum de comunistas e socialistas italianos, logo acusados de neofrentismo pelos seus oponentes, essa surgiu como um apelo à unidade e ao entendimento entre os partidos democráticos portugueses, sobretudo o PCP e o PS e entre esses e o MFA, como forma de superar a profunda crise que fraturava o panorama político em Lisboa durante o Verão Quente.

O período de maiores repercussões políticas situa-se, portanto, entre Março e Agosto de 1975. Os picos desse mediatismo ocorreram durante o congresso do PCI (18 a 23 
de Março) e a campanha eleitoral (18 de Maio a 13 de Junho). No primeiro caso, a polémica radicou no facto de os delegados da Democracia Cristã abandonarem os trabalhos da conferência em sinal de protesto para com o decreto dos militares portugueses que suspendia a atividade do PDC de Sanches Osório.

O secretário-geral da Democracia Cristã, Amintore Fanfani, tudo fez para passar a ideia de que era indestrutível o vínculo que unia os comunistas de Enrico Berlinguer, Secretário-geral do PCI, aos comunistas portugueses defensores das medidas antidemocráticas adotadas pelos militares de Abril. Em jeito de balanço, a revista Espresso afirmou que o partido de Cunhal não apenas se tinha inserido na reunião do PCI, fazendo-a, em parte, desviar do objetivo principal, como ainda havia reacendido, no movimento comunista internacional, uma velha e não resolvida questão: "come e in che modo i comunisti, dopo essere usciti dalla clandestinità e dal limbo dell'opposizione, riescono a garantire, una volta arrivati al potere, il libero esercizio e svolgimento della vita democratica" 13 .

No segundo caso, o jogo político continuou a apropriar-se de algumas das temáticas dimanadas pela Revolução de Abril, como constatou o diário bolonhês Il Resto del Carlino: "Gli ultimi avvenimenti del Portogallo (chiusura del giornale socialista ad opera dei comunisti) sono stati ieri l'argomento del giorno. [...] Non c'è dubbio che nel corso della campagna elettorale si continuerà a parlare del Portogallo quasi quanto dell'ordine pubblico" ${ }^{14}$.

Logo no início da campanha eleitoral, o "caso República", sempre visto como um braço-de-ferro entre o PCP e o PS, transformou-se num banco de dados disponível para municiar manchetes, narrativas jornalísticas e discursos políticos.

\footnotetext{
${ }^{13}$ Gianni Corbi, "La via italiana e il vicolo portoghese”, L'Espresso, 30-3-1975, p. 6.

14 “Il Portogallo e l'Italia del dopo-elezioni”, Il Resto del Carlino, 21-5-1975, p. 1.
} 
Os textos de jornalistas e analistas políticos convergem ao considerar Portugal um dos principais temas em foco neste período eleitoral, como demonstra, eloquentemente, Andrea Barbato ${ }^{15}$, em La Stampa: “C'è poi poco da stupirsi se i partiti parlino più del Portogallo che delle finanze locali: siamo politicamente presbiti, il garofano di Mario Soares ci sembra più vicino del deficit comunale, il Rossio di Lisbona più a portata di mano del campanile di casa".

O "caso República" e a campanha para as eleições Regionais e Administrativas encontraram a sociedade italiana numa atmosfera de profunda luta política caraterizada pelo discurso anticomunista da Democracia Cristã e pelos esforços de Enrico Berlinguer no sentido de, simultaneamente, desmistificar a dialética democrata-cristã e reafirmar a defesa das liberdades democráticas, o pluralismo político, a independência diante Moscovo, a permanência de Itália na Aliança Atlântica e na Comunidade Económica Europeia. A retórica que fazia recordar a doutrina Truman de contenção do expansionismo vermelho contava ainda com o contributo dos restantes setores conservadores, sempre disponíveis para engrossar as acusaçóes de que o PCI aplicava, habilmente, a conceção leninista de tomada do poder e da ditadura do proletariado.

Ao lado do confronto hegemónico entre democratas-cristãos e comunistas, polarizador de todas as atençôes, gravitava um PSI apostado em intrometer-se nesta equação bipolar e vincar a sua autonomia em relação ao PCI, em conquistar espaço e redimensionar a dominância conservadora da Democracia Cristã tendo em vista novos equilíbrios políticos, um novo modo de governar. No auge deste confronto político, a questão portuguesa transformou-se, em Itália, num seminal jogo de espelhos. Foi apropriada por socialistas, comunistas, liberais, democratas-cristãos, socialistasdemocráticos, repu-

\footnotetext{
${ }^{15}$ Andrea Barbato, "Con calma verso le elezioni”, La Stampa, 25-5-1975, p. 3.
} 
blicanos, pela extrema-direita e extrema-esquerda, assumindo, por isso, a figura de um octógono onde cada uma dessas oito correntes políticas explorava o lado que a representava e lhe conferia úteis elementos discursivos para disputar a luta simbólica pela defesa de uma determinada perspetiva do mundo social.

É esta a chave de leitura que deve nortear a compreensão do impacto da Revolução de Abril em Itália. Poucas vezes os eventos políticos portugueses assumiram tão vasta dimensão na imprensa internacional como no biénio 1974-1975. É seguro afirmar que a implantação da I República em 1910 teve fortes repercussões nos jornais além-fronteiras. Mas nunca com a intensidade e duração que caraterizaram o biénio revolucionário.

Quando, a 26 de Abril de 1974, o editorialista do Corriere della Sera, Michele Tito ${ }^{16}$, escreveu que a mais velha ditadura do Ocidente caía como os imperadores da Roma decadente, não estava, por certo, persuadido a imaginar que Portugal se iria deslocar da periferia para o centro do mundo. $\mathrm{O}$ país transformou-se numa espécie de workshop político para os círculos dirigentes, jornalísticos e intelectuais europeus, local de romagem para extrema-esquerda e ponto de fricção da ordem bipolar internacional da Guerra Fria que opunha o bloco ocidental ao bloco de leste.

\footnotetext{
${ }^{16}$ Michele Tito, "La tirannia più lunga", Corriere della Sera, 26-4-1974, p. 1.
} 


\section{BIBLIOGRAFIA}

Bakhtin, Mikhail Mikhailovich, Speech Genres and Other Late Essays, trad. Vern W. McGee, Austin, University of Texas Press, 1986.

Chaparro, Manuel Carlos, Pragmática do jornalismo: buscas práticas para uma teoria da ação jornalística, São Paulo, Summus, 1994.

Foucault, Michel, $A$ arqueologia do saber, trad. Miguel Serras Pereira, Coimbra, Almedina, 2005.

Galtung, Johan; Ruge, Mari Holmboe, "The Structure of Foreign News", Journal of Peace Research, 2, 1, 1965, pp. 64-91.

Goffman, Erving, Frame Analysis: an Essay on the Organization of Experience, Boston, Northeastern University Press, 1986.

Wolf, Mauro, Teorias da comunicação, trad. Maria Jorge Vilar de Figueiredo, Lisboa, Presença, 2001. 